\title{
International Partnerships in Ice Core Sciences (IPICS) Steering Committee meeting
}

\section{Vienna, Austria, 19-20 April 2008}

ERIC WolfF ${ }^{1}$ AND Ed Brook ${ }^{2}$

${ }^{1}$ British Antarctic Survey, Cambridge, UK; ewwo@bas.ac.uk

20regon State University, Corvallis, USA; brooke@geo.oregonstate.edu

Ice cores have become a cornerstone of research into climate and biogeochemistry, and have provided some of our iconic paleoclimate datasets. IPICS is a group of scientists, engineers and logistics experts from the leading laboratories and national operators carrying out ice core science. It was formed as a result of meetings in 2004 and 2005, and now has membership from 21 nations. Its mission includes defining priorities for ice core science and facilitating the steps to make the priority projects happen.

29 scientists and engineers, representing 16 of the IPICS nations, attended a meeting that followed the European Geosciences Union General Assembly. A fundamental aspect of IPICS is exchange of information about future plans, and this was achieved before the meeting by the preparation of a document with plans from each nation. This freed up time at the meeting for the main business, which was to approve science plans and outline implementation or coordination plans for the four IPICS priority projects.

One of the four priority projects is already underway: 14 nations have banded together to drill a new ice core (NEEM), with the intention of obtaining a complete record of the last interglacial from northwest Greenland. During that period, both the Arctic and Antarctic appear to have been warmer than present. Knowing precisely the climate signal and the ice sheet response in this period would place serious constraints on the impact of warming on ice sheet stability, highlighted by IPCC as one of the big unknowns for the next century and beyond. For this reason, the meeting discussed the option of building on the NEEM project to make a bipolar contribution to understanding the last interglacial, and a small group will consider this. Meanwhile, as of mid-May, 9 people are setting up the camp ready for drilling to start this summer.

The most ambitious IPICS project aims to extend the Antarctic ice core record beyond the 800-kyr period of EPICA Dome C. We know from marine data that $40 \mathrm{kyr}$ climate cycles prevailed (c.f., $100 \mathrm{kyr}$ ) before about a million years ago, and an ice core extending that far would allow us to assess, for example, the role of $\mathrm{CO}_{2}$ in this

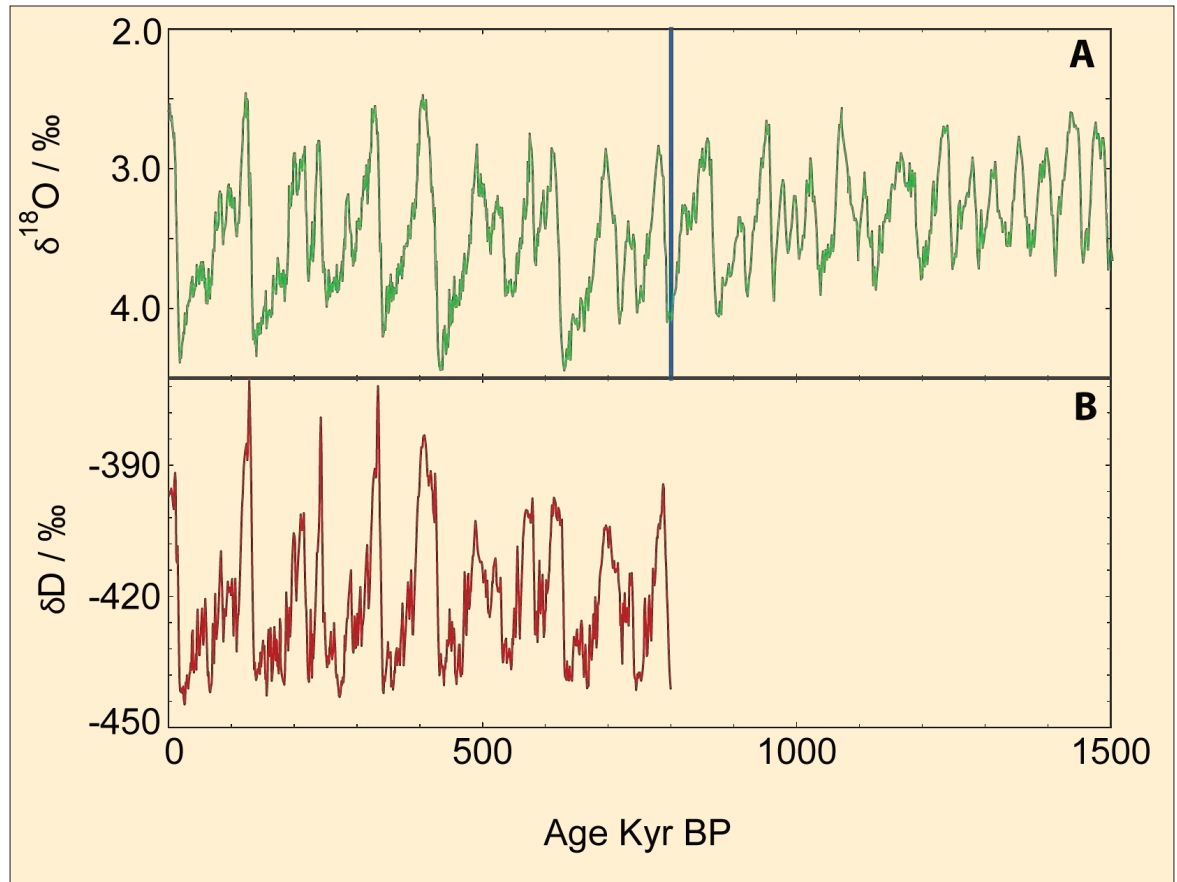

Figure 1: The ice core record (B; Jouzel et al., 2007) so far extends back $800 \mathrm{kyr}$, spanning only the period of $100 \mathrm{kyr}$ cycles. Marine records (A; Lisiecki and Raymo, 2005) show that 40-kyr cycles prevailed before about 1 Myr.

change of pace. A major survey and modeling program has to be completed before the drilling sites can be identified, and this will start with large airborne surveys in austral summer 2008/09. The meeting approved a plan that outlines the steps to be completed before a site is considered suitable, and agreed general principles for how international drilling and science consortia might work.

The third project aims to obtain a bipolar network of cores covering around $40 \mathrm{kyr}$, with the aim of understanding the spatial pattern of change during Dansgaard-Oeschger events and their Antarctic counterparts, and the last glacial termination. Many of the cores have already been drilled, and the members agreed where further cores should be encouraged, what measurements must be made, and the need for specific funded synthesis activities.

The final project will obtain a global set of ice cores extending back around 2000 years, suitable for inclusion in IPCCstyle reconstructions. The meeting agreed on the requirements for cores to be acceptable for such work, and again on the essential need for synthesis, involving the kind of stringent statistical study now done in some other communities with an- nually resolved data. Part of the discussion also focused on non-polar ice cores, and the urgent need to collect an archive of material from glaciers that are expected to melt in the near future.

Of course these projects require not just science but significant technical achievement, both in drilling, logging holes, proper curation of ice, and analysis. A technical sub-group is tasked with, for example, finding suitable drilling fluid for the oldest ice project. Sub-groups for each of the priority projects will pursue steps to make them a reality, and IPICS will have another formal meeting attached to the PAGES OSM in July 2009. For further information, please see www.pages-igbp.org/ ipics/

\section{References}

Jouzel, J. 2007: Orbital and Millennial Antarctic Climate Variability over the Past 800,000 Years, Science, 317(5839): 793-796, doi:10.1126/science.1141038.

Lisiecki, L.E., and Raymo, M.E., 2005: A Pliocene-Pleistocene stack of 57 globally distributed benthic $\mathrm{d}^{18} 0$ records, Paleoceanography, 20 PA1003, doi:10.1029/2004PA001071. 